\title{
Dynamic Behavior of Supported Structures from Free-Free Modal Tests Using Structural Dynamic Modification
}

\author{
G. Ismael, M. López-Aenlle $\mathbb{D}^{D}$, F. Pelayo $(\mathbb{D}$, and A. Fernández-Canteli \\ Department of Construction and Manufacturing Engineering, University of Oviedo, 33203 Gijón, Spain \\ Correspondence should be addressed to F. Pelayo; fernandezpelayo@uniovi.es
}

Received 8 August 2018; Revised 8 October 2018; Accepted 21 October 2018; Published 2 December 2018

Academic Editor: Nawawi Chouw

Copyright (c) 2018 G. Ismael et al. This is an open access article distributed under the Creative Commons Attribution License, which permits unrestricted use, distribution, and reproduction in any medium, provided the original work is properly cited.

\begin{abstract}
Several structures are completely or partially manufactured in a factory and then transported to the final situation where they are going to be located. An accurate methodology to check the serviceability of the structure in the factory, previously to the transportation and final assembly, will diminish significantly the costs of validation of its dynamic behavior. The structural dynamic modification (SDM) can be used to predict the modal parameters of a supported structure from the experimental modal parameters corresponding to the same structure but tested in a configuration easy to reproduce in a factory, such as the free-free condition. However, the accuracy obtained with this technique depends on how well the boundary conditions modelled with the SDM replicate the real support conditions. In this paper the SDM theory is used to predict the modal parameters of a pinned-free beam, a cantilever beam, and a 3D steel beam structure from the experimental natural frequencies and mode shapes of the same structures tested in free-free configuration. The predictions provided by the SDM theory are validated by operational modal testing on the supported structures. It is shown how the aforementioned boundary conditions can be modelled with the SDM, and the accuracy provided by the technique is investigated.
\end{abstract}

\section{Introduction}

Several types of structures are usually assembled in a factory or other manufacturing site and then transported to the construction site where the structure is to be located. The vibration serviceability state limit is one of the criteria that must be considered in the dynamic design of these structures in order to avoid resonances, which could cause structural damages or affect the comfort of the users [1-5]. For this reason, structural design codes establish frequency bands to be avoided, and the maximum acceptable acceleration levels in vertical and transversal directions are also limited $[6,7]$. Analytical and numerical models are generally used to predict the static and dynamic response of structures [8-10].

The analytical and numerical predictions can be validated by static tests (loading tests) or modal tests performed once the structure is fully assembled. This methodology requires moving personnel and equipment to the place where the structure is located in order to perform the tests which increases significantly the financing costs of the project if the structure, once in operation, needs some kind of reinforcements or repairs to be undertaken in order to fulfil the standards $[6,7]$.

The structural dynamic modification theory (SDM) [11-13] can be applied advantageously to validate the dynamic behavior of a structure in the factory, previously to the transportation and final assembly; that is, the modal parameters of a structure with the boundary conditions that it will have in operation are predicted from the experimental modal parameters measured in the factory.

In this paper, a methodology to predict the modal parameters of a structure, using the modal parameters corresponding to modal tests performed in the factory and the SDM theory, is presented. The technique consists of two steps. Firstly, the structure is tested using boundary conditions easy to reproduce in the factory/lab, such as the freefree condition (i.e., hanging the structure on two bridge cranes by means of flexible elements). In the second step, the natural frequencies and mode shapes of the structure with 
the new boundary conditions are predicted with SDM. In this case, the SDM consists of introducing the boundary conditions expected for the structure in operation and no mass or stiffness changes have to be considered. This means that the accuracy provided by the methodology only depends on how well the boundary conditions are modelled and the test setup and the identification techniques used in the modal tests.

The results provided by the methodology can be used to validate the structural design comparing the predictions obtained with the SDM with those provided by a numerical or analytical model.

In this paper, it is explained how to apply the methodology and the accuracy achieved with the SMD in simple structures with pinned and clamped boundary conditions is investigated. The modal parameters of a pinned-free beam, a cantilever beam, and a 3D beam structure are predicted using the SDM, and the modal parameters corresponding to the same structures are tested in free-free boundary conditions. The predicted modal parameters are validated with those obtained by operational modal tests performed on the supported structures.

\section{Theory of Structural Dynamic Modification}

The equation of motion of a multiple degree of freedom system with mass matrix $\left[M_{0}\right]$, damping matrix $\left[C_{0}\right]$, and stiffness matrix $\left[K_{0}\right]$, respectively, and subject to the force $\{F(t)\}$ is given by [10-13]

$$
\left[M_{0}\right]\{\ddot{x}\}+\left[C_{0}\right]\{\dot{x}\}+\left[K_{0}\right]\{x\}=\{F(t)\} .
$$

In this case, free vibration with proportional damping Equation (1) provides the following eigenvalue problem [10-13]:

$$
\left|\left[K_{0}\right]-\omega_{0}^{2}\left[M_{0}\right]\right|\left\{\varnothing_{0}\right\}=\{0\},
$$

where the eigenvalues $\omega_{0}^{2}$ represent the natural frequencies and the eigenvectors $\left\{\varnothing_{0}\right\}$ the mode shapes.

If the dynamic system given by Equation (1) is perturbed with the matrices $[\Delta M],[\Delta C]$, and $[\Delta K]$, respectively, the equation of motion of the perturbed system is expressed as [10-16]

$$
\left[M_{0}+\Delta M\right]\{\ddot{x}\}+\left[C_{0}+\Delta C\right]\{\dot{x}\}+\left[K_{0}+\Delta K\right]\{x\}=\{F(t)\} .
$$

Using modal decomposition, the responses can be written as a linear combination of the mode shape vectors by means of [10-13]

$$
\{x\}=\left[\varnothing_{0}\right]\{q\},
$$

where $\{q\}$ are the modal coordinates. If Equation (4) is substituted in Equation (3), the former becomes

$$
\begin{aligned}
& {\left[M_{0}+\Delta M\right]\left[\varnothing_{0}\right]\{\ddot{q}\}+\left[C_{0}+\Delta C\right]\left[\varnothing_{0}\right]\{\dot{q}\}} \\
& \quad+\left[K_{0}+\Delta K\right]\left[\varnothing_{0}\right]\{q\}=\{F(t)\} .
\end{aligned}
$$

Premultiplication of Equation (5) by $\varnothing_{0}^{\mathrm{T}}$ leads to

$$
\begin{aligned}
& {\left[\left[\varnothing_{0}\right]^{\mathrm{T}} M_{0}\left[\varnothing_{0}\right]+\left[\varnothing_{0}\right]^{\mathrm{T}} \Delta M\left[\varnothing_{0}\right]\right]\{\ddot{q}\}+\left[\varnothing_{0}\right]^{\mathrm{T}}\left[C_{0}\right]\left[\varnothing_{0}\right]\{\dot{q}\}} \\
& \quad+\left[\varnothing_{0}\right]^{\mathrm{T}}[\Delta C]\left[\varnothing_{0}\right]\{\dot{q}\}+\left[\left[\varnothing_{0}\right]^{\mathrm{T}} K_{0}\left[\varnothing_{0}\right]\right. \\
& \left.\quad+\left[\varnothing_{0}\right]^{\mathrm{T}} \Delta K\left[\varnothing_{0}\right]\right]\{q\}=\left[\varnothing_{0}\right]^{\mathrm{T}}\{F(t)\} .
\end{aligned}
$$

Taking into account that the eigenvectors of the unperturbed system satisfy the orthonormal conditions, the following are obtained:

$$
\begin{aligned}
{\left[\left[\varnothing_{0}\right]^{\mathrm{T}}[M]\left[\varnothing_{0}\right]\right] } & =[I], \\
{\left[\left[\varnothing_{0}\right]^{\mathrm{T}}[C]\left[\varnothing_{0}\right]\right] } & =[c], \\
{\left[\left[\varnothing_{0}\right]^{\mathrm{T}}[K]\left[\varnothing_{0}\right]\right] } & =\left[\omega_{0}^{2}\right],
\end{aligned}
$$

where $[c]$ is a diagonal matrix containing the terms $c_{i i}=2 \zeta_{i} \omega_{i}$, with $\zeta_{i}$ being the damping ratio of the $i$-th mode, Equation (6) can be expressed as

$$
\begin{gathered}
{\left[[I]+\left[\varnothing_{0}\right]^{\mathrm{T}} \Delta M\left[\varnothing_{0}\right]\right]\{\ddot{q}\}+\left[[c]+\left[\varnothing_{0}\right]^{\mathrm{T}}[\Delta C]\left[\varnothing_{0}\right]\right]\{\dot{q}\}} \\
+\left[\left[\omega_{0}^{2}\right]+\left[\varnothing_{0}\right]^{\mathrm{T}} \Delta K\left[\varnothing_{0}\right]\right]\{q\}=\left[\varnothing_{0}\right]^{\mathrm{T}}\{F(t)\},
\end{gathered}
$$

which provides the following eigenvalue problem:

$$
\begin{aligned}
& -\omega_{I}^{2}\left[[I]+\left[\varnothing_{0}\right]^{\mathrm{T}} \Delta M\left[\varnothing_{0}\right]\right]\{p\}+i \omega_{I}\left[[c]+\left[\varnothing_{0}\right]^{\mathrm{T}}[\Delta C]\left[\varnothing_{0}\right]\right]\{p\} \\
& +\left[\left[\omega_{0}^{2}\right]+\left[\varnothing_{0}\right]^{\mathrm{T}} \Delta K\left[\varnothing_{0}\right]\right]\{p\}=\{0\},
\end{aligned}
$$

where the subindex " $I$ " indicates perturbed system, $\omega_{I}$ are the eigenvalues, and $\{p\}$ are the eigenvectors. The perturbed mode shapes $\left[\varnothing_{I}\right]$ can be written as a linear combination of the unperturbed ones by means of [10-16]

$$
\left[\varnothing_{I}\right]=\left[\varnothing_{0}\right][P],
$$

where $[P]$ are the eigenmatrixes. From Equations (8) and (9), it is inferred that the modal parameters of a structure with new boundary conditions (perturbed structure) can be predicted if the modal parameters of the unperturbed structure, together with the mass, stiffness, and damping change matrices, are known.

\section{Application to a Steel Beam}

3.1. Description of the Structure. A two-meter long steel cantilever beam with a rectangular hollow section was used in the investigation. The mechanical and material properties considered for the beam are shown in Table 1.

3.2. Free-Free Experimental Tests. The beam was initially tested in free-free configuration using OMA. In order to reproduce the free-free conditions, the beam was initially suspended using two springs as it is shown in Figure 1. Twenty-one uniformly distributed PCB 333B32 accelerometers with a sensitivity of $100 \mathrm{mV} / \mathrm{g}$ were attached to the beam (Figure 2) in order to identify the bending modes in both axes 
TABLE 1: Mechanical and material properties of the beam.

\begin{tabular}{lcccc}
\hline Section $(\mathrm{mm})$ & Young's modulus $(\mathrm{Pa})$ & Inertia (strong axis, $X)\left(\mathrm{cm}^{4}\right)$ & Inertia (weak axis, $Y)\left(\mathrm{cm}^{4}\right)$ & Mass per unit length $(\mathrm{kg} / \mathrm{m})$ \\
\hline RHS $80 \times 40 \times 4$ & $2.1 \times 10^{11}$ & 64.8 & 21.5 & 13.9 \\
\hline
\end{tabular}
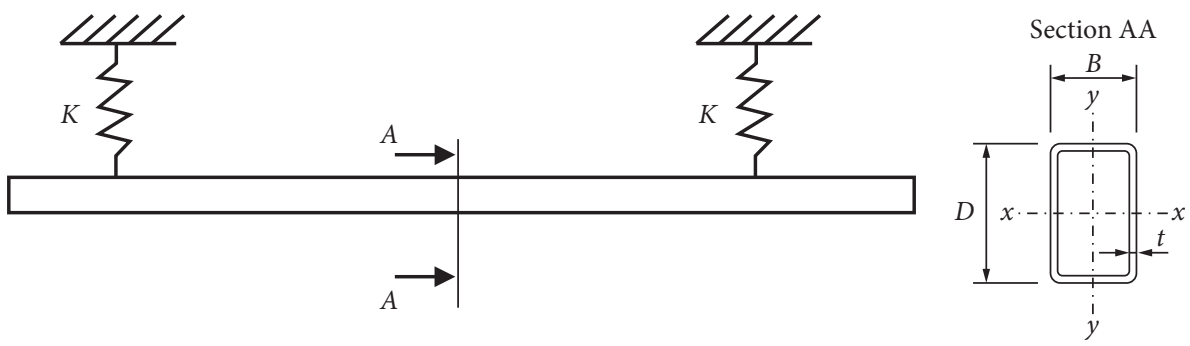

Figure 1: Beam in free-free configuration.

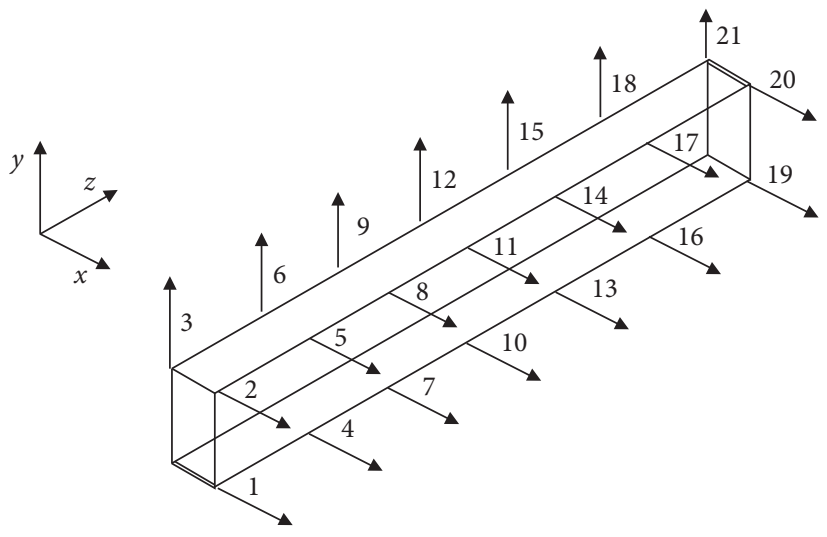

Figure 2: Test setup for the free-free configuration.

(strong or $X$-axis and weak or $Y$-axis). The structure was excited by applying several hits along the beam randomly in time and space using an impact hammer, and the acceleration responses were recorded with a sampling frequency of $2132 \mathrm{~Hz}$ during a period of approximately 10 minutes using a national instruments digital acquisition system.

The experimental modal parameters were identified from the experimental responses with the frequency-domain decomposition (FDD) technique $[13,17]$. The singular value decomposition (SVD) of the responses is shown in Figure 3.

Thirteen modes were identified in the range of $0-$ $1066 \mathrm{~Hz}$. Six modes correspond to the strong axis $(X)$ and seven to the weak axis $(Y)$. The first four modes are rigid body modes (two with respect to the weak axis, and two with respect to the strong axis), while the remaining ones are bending modes. Torsional modes were not considered in this paper. The natural frequencies and the mode shapes with respect to the weak axis are shown in Table 2.

Moreover, although the numerical model is not needed in the proposed methodology, a finite element model was assembled using the program LISA 8.0 [18]. Linear EulerBernoulli beam elements with two nodes and six DOFs per node were used in the simulations. The numerical natural frequencies and the mode shapes are also included in Table 2.
3.3. Pinned-Free Configuration. The SDM theory was applied to predict the natural frequencies and mode shapes of the beam in the pinned-free configuration with respect to both strong and weak axis.

The methodology followed to predict the modal parameters will be described in detail for the weak axis. The first six experimental mode shapes (scaled to the maximum component equal to unity) of the free-free beam (weak axis) were considered in the predictions (Table 2) which are given by

$$
\left[\varnothing_{0}\right]=\left(\begin{array}{cccccc}
1 & -1 & 0.98 & -0.98 & 0.97 & -0.93 \\
1 & -0.66 & 0.24 & 0.23 & 0.57 & 0.70 \\
1 & -0.33 & -0.30 & 0.71 & 0.40 & -0.32 \\
1 & 0 & -0.65 & 0 & 0.79 & 0 \\
1 & 0.33 & -0.39 & -0.70 & -0.19 & 0.56 \\
1 & 0.66 & 0.24 & -0.23 & -0.54 & -0.66 \\
1 & 1 & 1 & 1 & 1 & 1
\end{array}\right) \text {, }
$$

where each column represents a mode shape and each row represents the corresponding measured DOF (Figure 4). In the operational modal analysis, the excitation force is unknown and the mode shapes cannot be mass normalized 


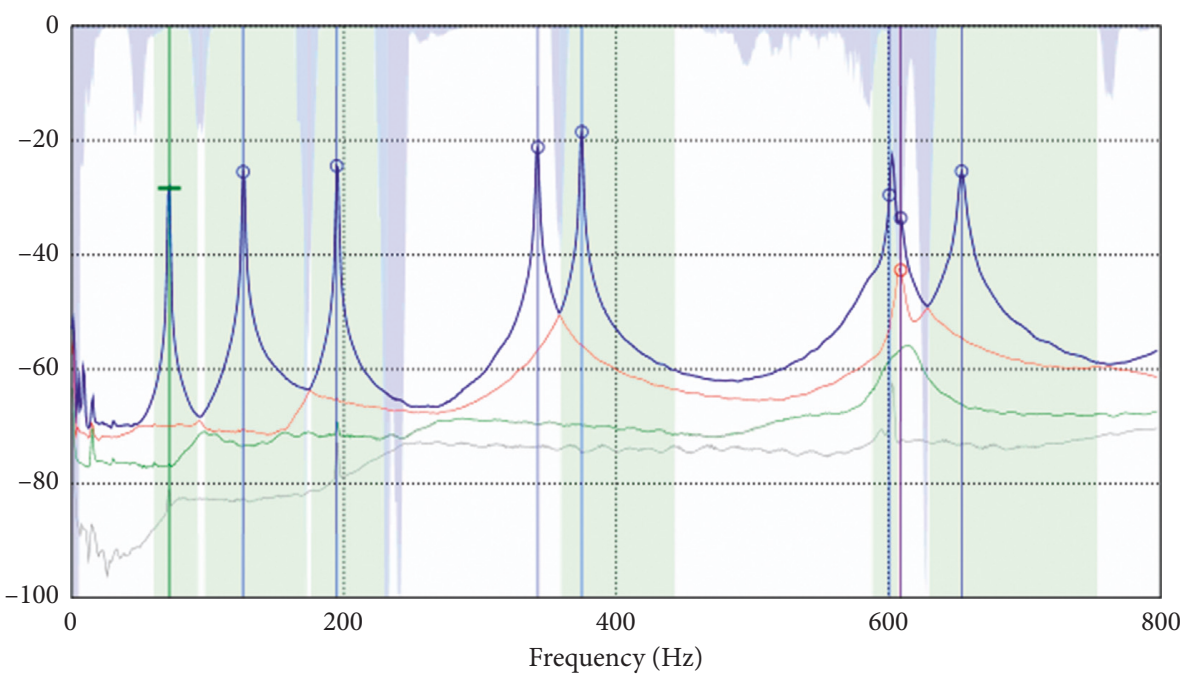

FIgURE 3: Singular value decomposition for the beam under free-free conditions from 0 to $750 \mathrm{~Hz}$.

TABle 2: Experimental and numerical natural frequencies for the free-free configuration.

\begin{tabular}{|c|c|c|c|c|c|c|c|}
\hline \multirow{3}{*}{ Mode } & \multirow{3}{*}{ Mode shape } & \multicolumn{6}{|c|}{ Natural frequency $(\mathrm{Hz})$} \\
\hline & & \multicolumn{3}{|c|}{ Weak axis $(Y)$} & \multicolumn{3}{|c|}{ Strong axis $(X)$} \\
\hline & & Numerical & Experimental & Error (\%) & Numerical & Experimental & Error (\%) \\
\hline 1 & & $\approx 0$ & 0.5 & - & $\approx 0$ & 0.5 & - \\
\hline 2 & & $\approx 0$ & 0.6 & - & $\approx 0$ & 0.6 & - \\
\hline 3 & & 73.78 & 71.4 & 3.33 & 129.73 & 125.96 & 2.99 \\
\hline 4 & & 203.57 & 195.14 & 4.32 & 357.62 & 342.49 & 4.42 \\
\hline 5 & & 398.77 & 374.50 & 6.48 & 701.10 & 653.75 & 7.24 \\
\hline 6 & & 659.17 & 600.67 & 9.74 & 1159.09 & 1047.2 & 10.68 \\
\hline 7 & & 984.89 & 868.21 & 13.44 & 1731.83 & - & - \\
\hline
\end{tabular}

$[13,19,20]$. The mass-normalized mode shapes $\{\phi\}$ are related to the unscaled mode shapes $\{\psi\}$ by the following equation:

$$
\{\phi\}=\{\psi\} \alpha,
$$

where $\alpha$ is the scaling factor, which can be calculated with the following expression [10-12]:

$$
\alpha=\frac{1}{\{\psi\}^{\mathrm{T}}[M]\{\psi\}} .
$$

In this paper, a lumped mass matrix was assembled in order to scale the mode shapes. This model is expected to provide good results because the mass is uniformly distributed and the mass of the beam is known (it was previously weighted).
The analytical natural frequencies and the mode shapes were predicted using the eigenvalue problem given by Equation (9) where the effect of damping was neglected. As there is no coupling between the bending modes with respect to the weak axis and those with respect to the strong axis (in both free-free and pinned-free configurations), the modal parameters of each case were calculated separately.

To predict the pinned-free case using SDM, the analytical model presented in Figure 4 was used, where each DOF correspond to a sensor location. A spring with stiffness $\Delta K_{\mathrm{u}}$ (Figure 4) was introduced to simulate the pin support. The stiffness magnitude was chosen after conducting a sensitivity analysis using different values of $\Delta K_{u}$. The evolution of the first five natural frequencies for 


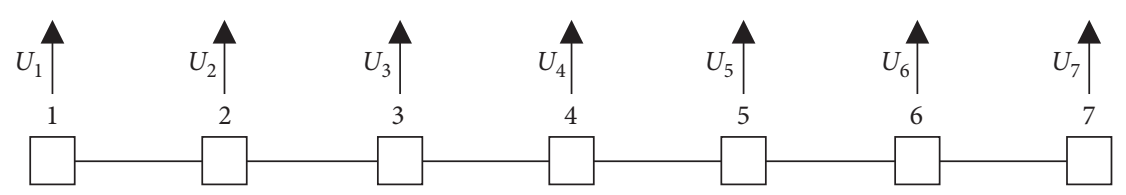

(a)

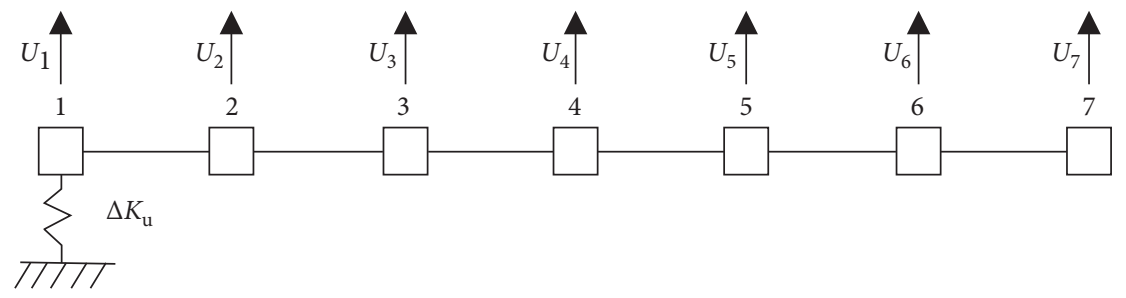

(b)

Figure 4: Analytical model of the (a) free-free and (b) pinned-free configurations.

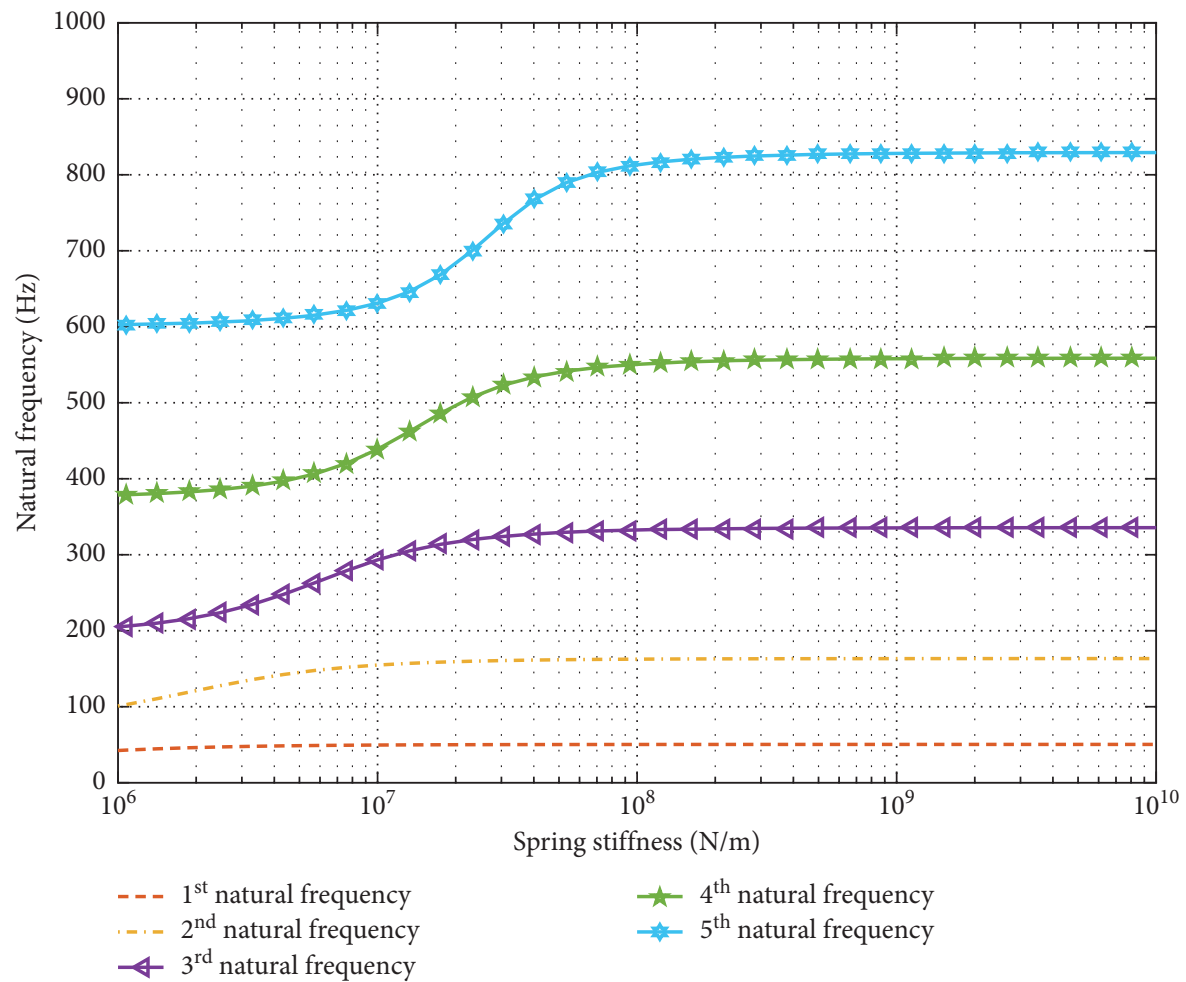

FIgUre 5: Analytical natural frequencies obtained for different spring stiffness $\Delta K_{\mathrm{u}}$ ( $X$-axis).

different values of $\Delta K_{u}$ is shown in Figure 5 from which it is inferred that the natural frequencies remain unchanged for values $\Delta K_{\mathrm{u}} \geq 10^{8} \mathrm{~N} / \mathrm{m}$. On the contrary, the translational components of a mode shape in a pinned support must be zero. The magnitudes of the first component (DOF1) for each mode shape, considering different stiffness values $\Delta K_{\mathrm{u}}$, are shown in Figure 6. From Figures 5 and 6 , it is inferred that a stiffness $\Delta K_{\mathrm{u}}=10^{8} \mathrm{~N} / \mathrm{m}$ guarantees that the behavior of the beam is pinned-free for the first five modes considered in the investigation.

Therefore, the following stiffness change matrix was used in the analytical predictions:

$$
[\Delta K]=\left(\begin{array}{cccccc}
1 \times 10^{10} & 0 & 0 & 0 & 0 & 0 \\
0 & 0 & 0 & 0 & 0 & 0 \\
0 & 0 & 0 & 0 & 0 & 0 \\
0 & 0 & 0 & 0 & 0 & 0 \\
0 & 0 & 0 & 0 & 0 & 0 \\
0 & 0 & 0 & 0 & 0 & 0
\end{array}\right),
$$

whereas it was assumed that $\Delta M=0$ and $\Delta C=0$.

In order to reproduce experimentally the pinned boundary condition with respect to the weak axis, the 


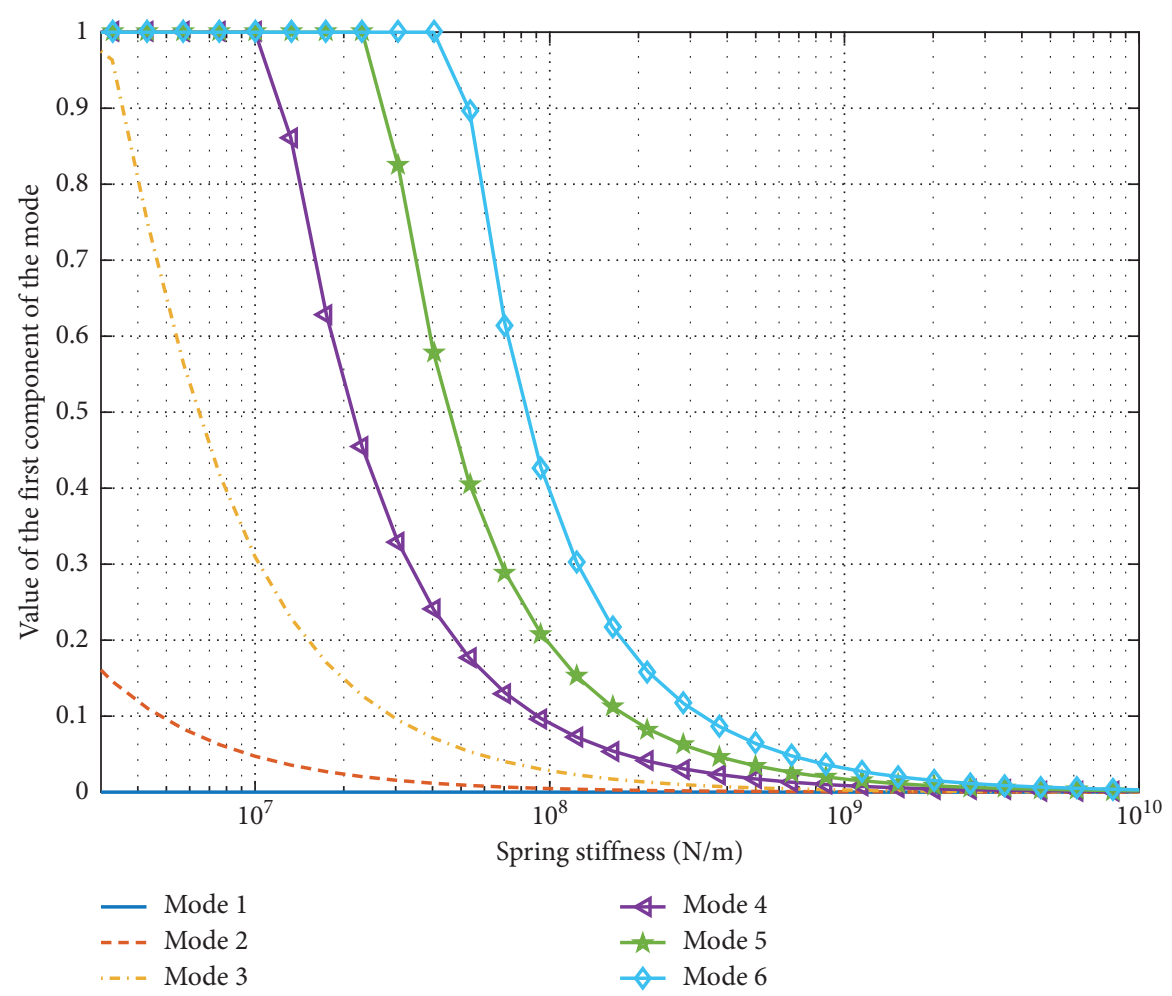

FIGURE 6: First component of the predicted mode shapes for different values of $\Delta K_{\mathrm{u}}$ ( $X$-axis).

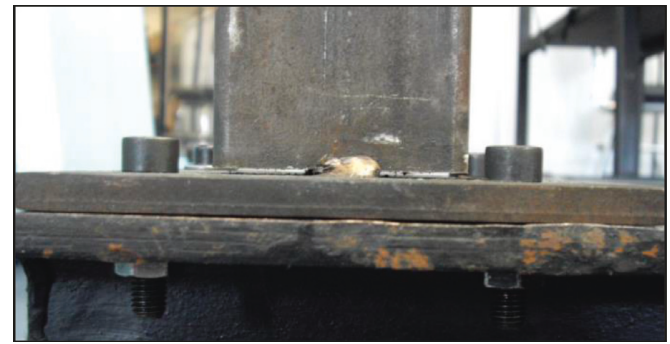

(a)

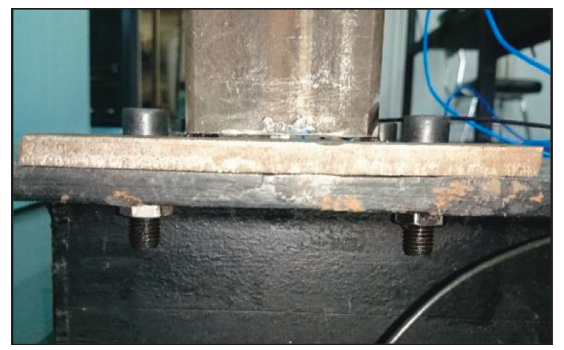

(b)

Figure 7: Detail of the weld bead along the long side (a) and short side (b).

beam was welded to a plate as it is shown in Figure 7; that is, the beam was welded with two short weld beads along the short sides. These shorts weld beads guarantee that the rotation is free with respect to the weak axis, whereas the displacement is not permitted. The plate was fastened with four screws to a steel foundation clamped to the concrete floor (Figure 7).

The same methodology was followed with respect to the strong axis. The experimental modes were identified by OMA, and the natural frequencies estimated with the FDD technique are shown in Table 3. Moreover, a pinned-free FE model was assembled to predict the modal parameters of the pinned-free beam with respect to both axes. The numerical natural frequencies estimated are also shown in Tables 3 and 4 .

From Tables 3 and 4, it can be inferred that the natural frequencies of the pinned-free configuration can be predicted with a good accuracy, the error between the experimental and the predicted natural frequencies being less than $5 \%$ for both axes. It can also be observed that the maximum error obtained with SDM is less than the obtained with the numerical model.

The modal assurance criterion (MAC) between the experimental and the analytical mode shapes predicted with Equation (9) are shown in Table 5. It can be observed that the mode shapes have been predicted with a good accuracy $(\mathrm{MAC}>0.95)$ for the first five modes, with respect to the weak axis, and for the first three modes, with respect to the strong axis. Due to the fact that a truncated model (free-free experimental test) is used to predict the modal parameters of the pinned-free beam, the mode shapes and the natural frequencies of the higher modes are predicted with less accuracy. This is expected because the mode shapes of the pinned-free beam are obtained as a linear combination of 
TABLE 3: Natural frequencies of the pinned-free beam with respect to the strong axis $(X)$.

\begin{tabular}{lccccc}
\hline Mode & & Natural frequency $(\mathrm{Hz})$ & \multicolumn{2}{c}{ Error (\%) } \\
& Experimental & Predicted (Equation (9)) & Numerical & Experimental - predicted & - \\
Experimental - numerical \\
\hline 1 & 0.64 & 0 & 0 & - & 0.44 \\
2 & 89.01 & 90.64 & 89.40 & 2.45 & 4.65 \\
3 & 279.51 & 286.53 & 289.72 & 0.42 & 6.35 \\
4 & 568.4 & 570.78 & 604.51 & 2.83 & 10.04 \\
5 & 939.52 & 913.62 & 1033.84 & & \\
\hline
\end{tabular}

TABLe 4: Natural frequencies of the pinned-free beam with respect to the weak axis $(Y)$.

\begin{tabular}{|c|c|c|c|c|c|}
\hline \multirow{2}{*}{ Mode } & \multicolumn{3}{|c|}{ Natural frequency $(\mathrm{Hz})$} & \multicolumn{2}{|c|}{ Error (\%) } \\
\hline & Experimental & Predicted (Equation (9)) & Numerical & Experimental - predicted & Experimental - numerical \\
\hline 1 & 5.72 & 0 & 0 & - & - \\
\hline 2 & 52.73 & 50.42 & 50.84 & 4.39 & 3.72 \\
\hline 3 & 161.88 & 163.38 & 164.77 & 0.92 & 1.75 \\
\hline 4 & 327.26 & 335.64 & 343.785 & 2.56 & 4.81 \\
\hline 5 & 541.98 & 558.61 & 587.94 & 3.07 & 7.82 \\
\hline 6 & 792.48 & 829.24 & 897.333 & 4.64 & 11.68 \\
\hline
\end{tabular}

TABLE 5: MAC between the experimental and the analytical mode shapes.

\begin{tabular}{lccccccccccc}
\hline Mode & \multicolumn{3}{c}{ Strong axis $(X)$} & \multicolumn{5}{c}{ Weak axis $(Y)$} \\
& 1 & 2 & 3 & 4 & 5 & 1 & 2 & 3 & 4 & 5 \\
\hline 1 & 1.00 & 0.06 & 0.06 & 0.06 & 0.06 & 1.00 & 0.08 & 0.07 & 0.06 & 0.10 & 0.07 \\
2 & 0.05 & 1.00 & 0.10 & 0.09 & 0.10 & 0.05 & 1.00 & 0.07 & 0.13 & 0.07 & 0.08 \\
3 & 0.05 & 0.05 & 0.99 & 0.10 & 0.06 & 0.06 & 0.09 & 1.00 & 0.05 & 0.14 & 0.10 \\
4 & 0.03 & 0.12 & 0.05 & 0.93 & 0.14 & 0.06 & 0.09 & 0.09 & 0.97 & 0.08 & 0.12 \\
5 & 0.07 & 0.07 & 0.10 & 0.10 & 0.80 & 0.07 & 0.08 & 0.08 & 0.16 & 0.97 & 0.09 \\
6 & - & - & - & - & - & 0.05 & 0.05 & 0.11 & 0.06 & 0.18 & 0.93 \\
\hline
\end{tabular}

a low number of mode shapes of the free-free configuration $[15,21]$.

3.4. Fixed-Free Cantilever Configuration. A similar procedure was followed to predict the modal parameters of the fixed-free configuration (cantilever). The beam was fixed by welding two steel plates (B) $6 \mathrm{~mm}$ thick to both beam and horizontal plate (A) (Figure 8).

The analytical model shown in Figure 9, where both displacement and rotation at node 1 have to be restrained, was used for predicting the modal parameters of the fixedfree beam from the results of the free-free configuration. Due the fact that the rotations were not measured in the free-free experimental tests, the experimental mode shapes have been expanded using the local correspondence principle [21]. The free-free expanded mode shapes (seven translational and seven rotational DOFs), normalized to maximum component equal to unity, are given by

$$
\left[\varnothing_{0}\right]=\left(\begin{array}{ccccccc}
1 & -1 & 0.98 & -0.97 & 0.97 & -0.93 & -0.93 \\
0 & 1 & -2.7 & 3.84 & -6.72 & -6.72 & 14.02 \\
1 & -0.67 & 0.24 & 0.23 & -0.57 & -0.57 & 0.70 \\
0 & 1 & -1.83 & 2.95 & -2.26 & -2.26 & -1.66 \\
1 & -0.33 & -0.3 & 0.71 & -0.4 & -0.40 & -0.32 \\
0 & 1 & -1.48 & -0.54 & 3.5 & 3.50 & -1.85 \\
1 & 0 & -0.65 & 0 & 0.79 & 0.79 & 0.01 \\
0 & 1 & -0.22 & -2.91 & 0.47 & 0.47 & 2.83 \\
1 & 0.33 & -0.4 & -0.70 & -0.19 & -0.19 & 0.56 \\
0 & 1 & 1.5 & -0.53 & -3.52 & -3.52 & -1.56 \\
1 & 0.67 & 0.24 & -0.23 & -0.54 & -0.54 & -0.66 \\
0 & 1 & 2.2 & 2.97 & 1.58 & 1.58 & -2.55 \\
1 & 1 & 1 & 1 & 1 & 1 & 1 \\
0 & 1 & 2.26 & 3.99 & 7.88 & 7.88 & 15.69
\end{array}\right),
$$




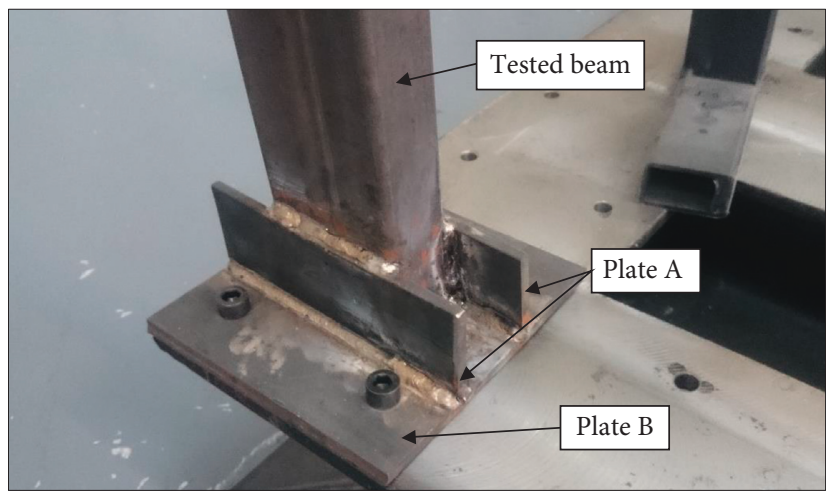

FIGURE 8: Details of the fixed support of the free configuration.

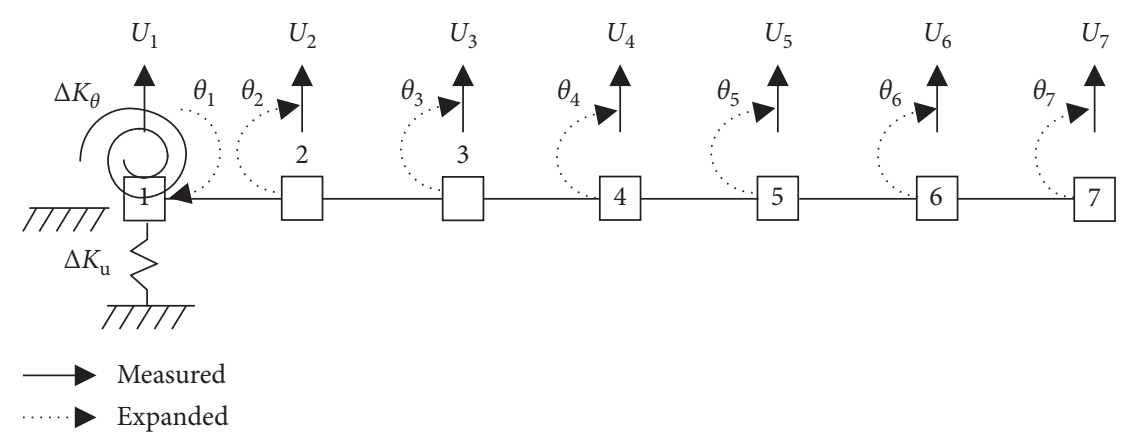

FIgURE 9: Analytical model for the fixed-free configuration.

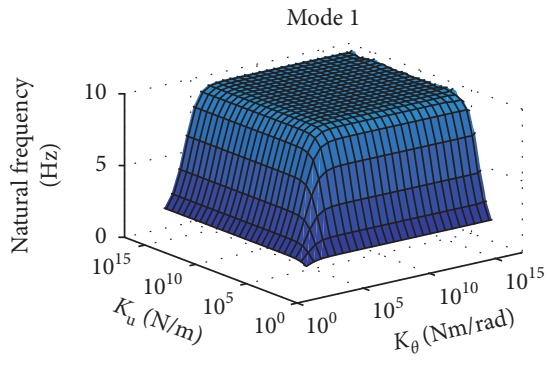

Mode 1

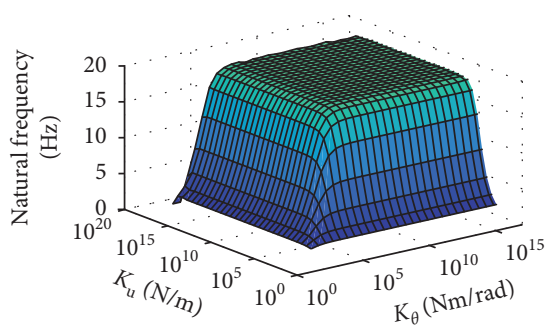

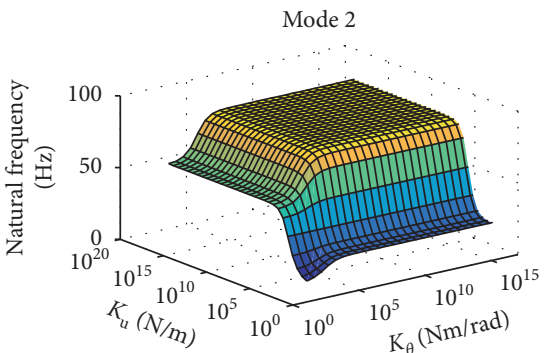

(a)

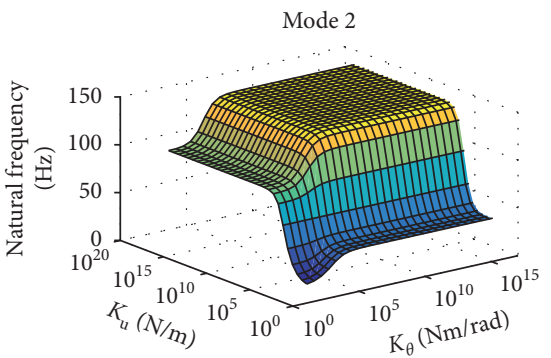

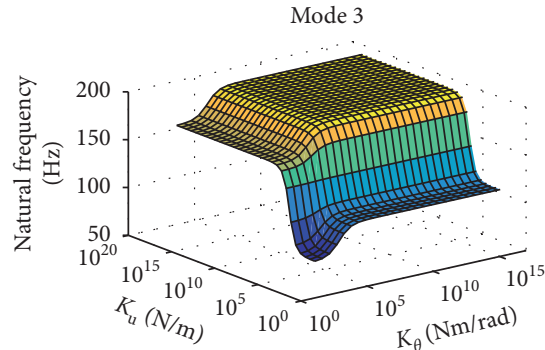

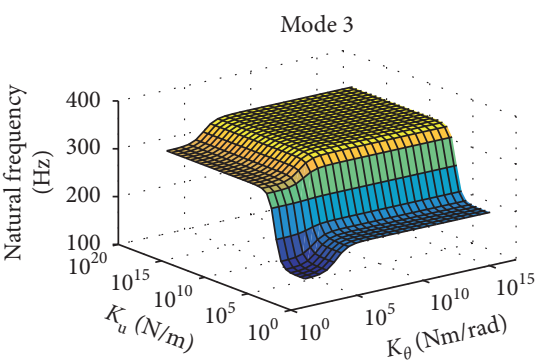

(b)

Figure 10: Evolution of the natural frequencies for different $\Delta K_{u}$ and $\Delta K_{\theta}$ combinations. Fixed-free configuration. (a) Weak Axis ( $Y$ ). (b) Strong Axis $(X)$.

where each column represents a mode shape and the rows represent the DOF's (the odd rows are displacements and the even ones rotations). The mode shape matrix given by Equation (15) was considered for both directions (strong and weak axes). The modes were normalized to the mass assuming the entire amount of mass is concentrated evenly in the DOFs.

The fixed boundary conditions for the analytical model were simulated by adding two springs $\Delta K_{u_{1}}=1 \times 10^{10} \mathrm{~N} / \mathrm{m}$ 


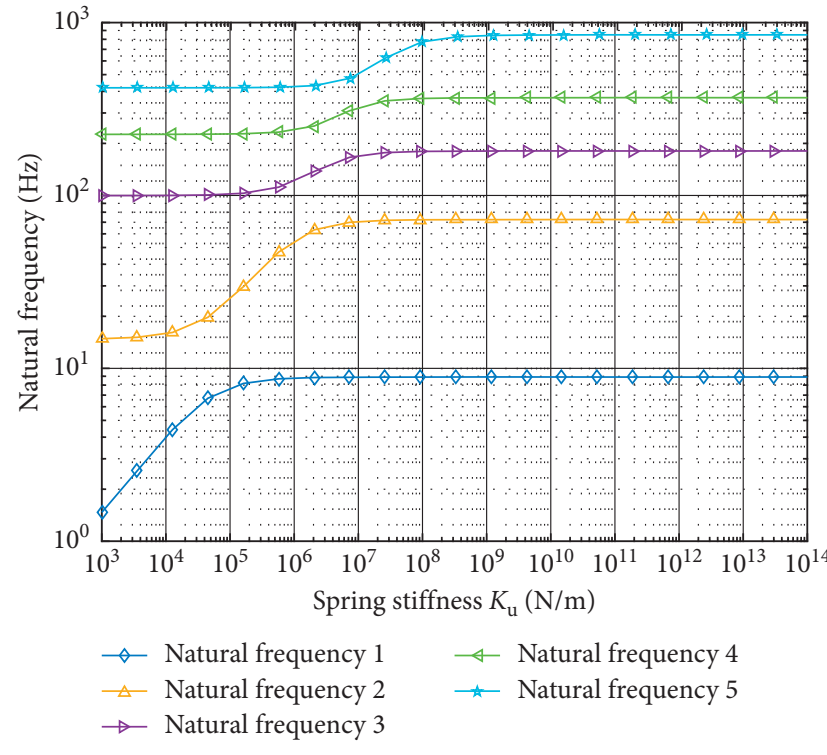

(a)

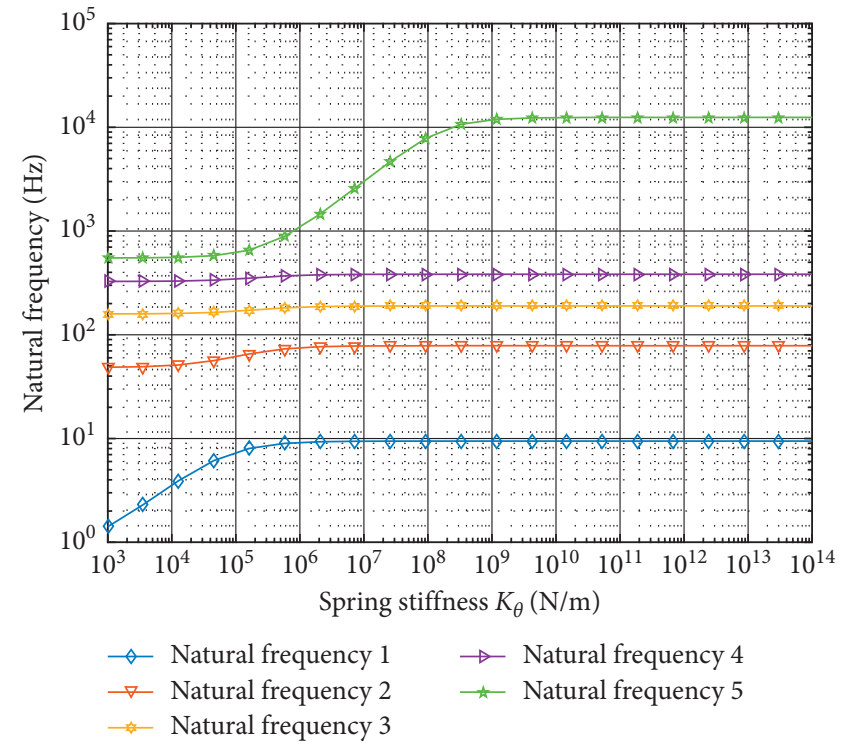

(b)

Figure 11: Evolution of the natural frequencies for different values of (a) $\Delta K_{u}\left(\Delta K_{\theta}=8 \times 10^{5} \mathrm{Nm} / \mathrm{rad}\right)$ and (b) $\Delta K_{\theta}\left(\Delta K_{u_{1}}=1 \times 10^{10} \mathrm{Nm}\right)$. Fixed-free configuration ( $X$-axis).

and $\Delta K_{\theta_{1}}=8 \times 10^{5} \mathrm{~N} \cdot \mathrm{m} / \mathrm{rad}$, respectively, in node 1 (Figure 9). The stiffness change matrix is expressed as

$$
[\Delta K]=\left(\begin{array}{ccccccc}
\Delta K_{u_{1}}=1 \times 10^{10} & 0 & 0 & 0 & 0 & 0 & \ldots \\
0 & \Delta K_{\theta_{1}}=8 \times 10^{5} & 0 & 0 & 0 & 0 & \ldots \\
0 & 0 & 0 & 0 & 0 & 0 & \ldots \\
0 & 0 & 0 & 0 & 0 & 0 & \ldots \\
0 & 0 & 0 & 0 & 0 & 0 & \ldots \\
0 & 0 & 0 & 0 & 0 & 0 & \ldots \\
\ldots & \ldots & \ldots & \ldots & \ldots & \ldots & \ldots
\end{array}\right) .
$$

The magnitude of the springs stiffnesses was established using the same procedure as that followed for the pinnedfree configuration. The evolution of the natural frequencies for different values of $\Delta K_{u_{1}}$ and $\Delta K_{\theta_{1}}$ is shown in Figures 10 and 11 , respectively, whereas the first component of the mode shapes is presented in Figure 12.

The predicted natural frequencies together with the experimental ones identified by operational modal analysis using the FDD technique are shown in Table 6. It can be observed that the discrepancies between the experimental and the predicted natural frequencies are higher than those obtained for the pinned-free configuration, the maximum error for all the modes in both axes being approximately $16 \%$. A larger error is expected in this case because, on one hand, it is difficult to have a perfect fixed boundary condition in real structures and, on the other hand, the plates B (Figure 8) used to fix the beam change slightly the length of the beam; that is, the cantilever tested beam has a different length to that tested in the free-free configuration. Consequently, it is not possible to discriminate the influence of SDM theory and that which comes from an imperfect fixed support or from changes in the length of the beam in the discrepancies. The values $\Delta K_{u_{1}}$ and $\Delta K_{\theta_{1}}$ considered in the predictions correspond to a perfect clamping.

The MAC between the predicted and the experimental mode shapes is shown in Table 7. It can be observed that there is a good correlation for the first four modes, but the error increases with the order of the mode. This is in agreement with the results obtained by Avitabile [16] where it is demonstrated that, for a cantilever beam, the unperturbed system (the free-free system) must contain a sufficient set of vectors to describe the modified system accurately. Thus, many modes are necessary to predict the modal parameters of a cantilever with a reasonable accuracy.

From Tables 6 and 7, it can be inferred that the natural frequencies and the mode shapes of the lower frequency modes of a cantilever beam can be predicted with a reasonable accuracy from a free-free system using the structural dynamic modification theory if an appropriate set of modes is considered and the experimental boundary conditions can be reproduced with a reasonable accuracy in the analytical model.

\section{Application to a Steel Beam Structure}

The steel beam structure shown in Figure 13 was used to validate the structural dynamic modification theory in a more complex case. The structure consists of four steel rectangular hollow section beams $(50 \times 30 \times 3 \mathrm{~mm})$ welded in points $1,2,3$, and 4 . The dimensions of the structure are 


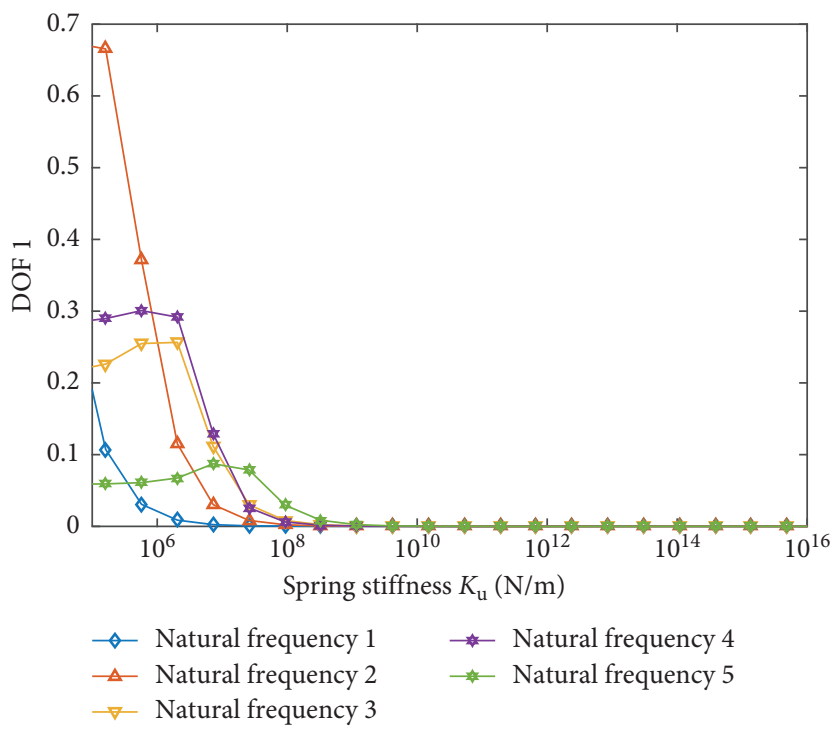

Figure 12: Evolution of the first component of the mode shapes for different values of $\Delta K_{u}$ and $\Delta K_{\theta}=8 \times 10^{5}$ (SI units). Fixed-free configuration ( $Y$-axis).

TABLE 6: Experimental and predicted natural frequencies for the fixed-free configuration.

\begin{tabular}{|c|c|c|c|c|c|c|}
\hline \multirow{3}{*}{ Mode } & \multicolumn{3}{|c|}{ Weak axis $(Y)$} & \multicolumn{3}{|c|}{ Strong axis $(X)$} \\
\hline & \multicolumn{2}{|c|}{ Natural frequencies $(\mathrm{Hz})$} & \multirow{2}{*}{$\begin{array}{c}\text { Error } \\
\text { Experimental - predicted } \\
(\%)\end{array}$} & \multicolumn{2}{|c|}{ Natural frequencies $(\mathrm{Hz})$} & \multirow{2}{*}{$\begin{array}{c}\text { Error } \\
\text { Experimental - predicted } \\
(\%)\end{array}$} \\
\hline & $\begin{array}{l}\text { Experimental } \\
\text { frequency }\end{array}$ & $\begin{array}{l}\text { Frequency predicted } \\
\quad \text { (Equation }(9))\end{array}$ & & $\begin{array}{l}\text { Experimental } \\
\text { frequency }\end{array}$ & $\begin{array}{l}\text { Frequency predicted } \\
\quad(\text { Equation }(9))\end{array}$ & \\
\hline 1 & 10.93 & 9.55 & 12.60 & 15.617 & 15.67 & 0.33 \\
\hline 2 & 67.69 & 78.09 & 15.36 & 103.25 & 117.87 & 14.16 \\
\hline 3 & 186.88 & 185.90 & 0.53 & 296.6 & 305.81 & 3.11 \\
\hline 4 & 362.91 & 377.11 & 3.91 & 573.72 & 611.66 & 6.61 \\
\hline 5 & 570.67 & 1075.59 & $>100.00$ & 1016.21 & 1064.90 & $>100.00$ \\
\hline 6 & 825.29 & 2291.05 & $>100.00$ & - & 2280.30 & $>100.00$ \\
\hline
\end{tabular}

TABLE 7: MAC between experimental and predicted mode shapes.

\begin{tabular}{|c|c|c|c|c|c|c|c|c|c|c|c|c|}
\hline \multirow{3}{*}{ Mode } & \multicolumn{11}{|c|}{ MAC } & \\
\hline & \multicolumn{6}{|c|}{ Weak axis $(Y)$} & \multicolumn{6}{|c|}{ Strong axis $(X)$} \\
\hline & 1 & 2 & 3 & 4 & 5 & 6 & 1 & 2 & 3 & 4 & 5 & 6 \\
\hline 1 & 1.00 & 0.09 & 0.06 & 0.10 & 0.13 & 0.00 & 1.00 & 0.09 & 0.07 & 0.08 & 0.08 & - \\
\hline 2 & 0.07 & 1.00 & 0.08 & 0.12 & 0.09 & 0.00 & 0.05 & 0.96 & 0.20 & 0.06 & 0.09 & - \\
\hline 3 & 0.08 & 0.12 & 0.99 & 0.08 & 0.18 & 0.00 & 0.05 & 0.03 & 0.95 & 0.18 & 0.03 & - \\
\hline 4 & 0.08 & 0.08 & 0.09 & 0.92 & 0.10 & 0.00 & 0.09 & 0.15 & 0.06 & 0.81 & 0.49 & - \\
\hline 5 & 0.07 & 0.09 & 0.05 & 0.31 & 0.59 & 0.04 & 0.03 & 0.02 & 0.04 & 0.01 & 0.31 & - \\
\hline 6 & 0.07 & 0.10 & 0.09 & 0.07 & 0.67 & 0.10 & - & - & - & - & - & - \\
\hline
\end{tabular}

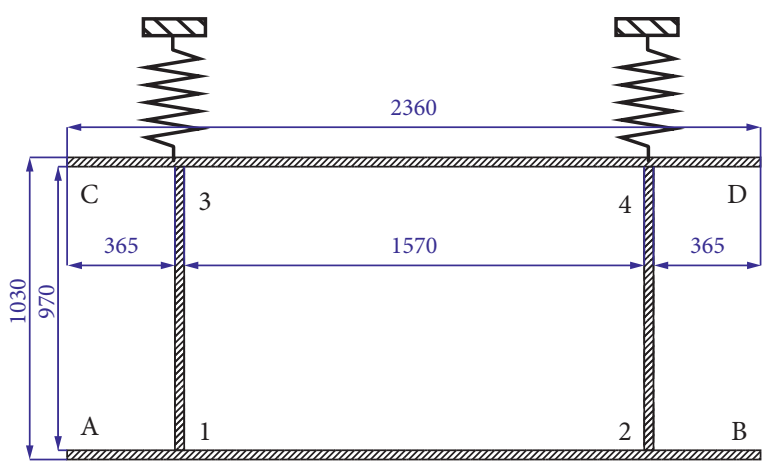

(a)

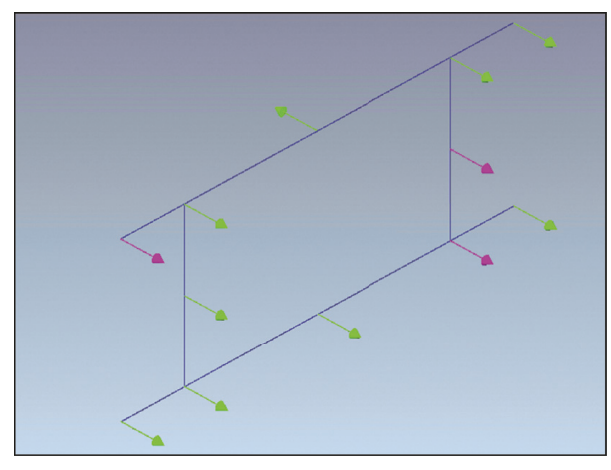

(b)

FIGURE 13: Geometry of the structure (a) and the setup for the free-free configuration (b). 
TABLE 8: Experimental and numerical natural frequencies obtained for free-free configuration.

\begin{tabular}{|c|c|c|c|}
\hline \multirow{2}{*}{ Mode } & \multicolumn{2}{|c|}{ Natural frequencies $(\mathrm{Hz})$} & \multirow{2}{*}{ Error $(\%)$} \\
\hline & Experimental & Numerical & \\
\hline 1 & 23.15 & 23.65 & 2.16 \\
\hline 2 & 27.83 & 30.13 & 8.26 \\
\hline 3 & 46.24 & 48.03 & 3.88 \\
\hline 4 & 56.02 & 57.06 & 1.86 \\
\hline 5 & 70.58 & 71.07 & 1.84 \\
\hline 6 & 65.90 & 71.87 & 7.86 \\
\hline 7 & 102.70 & 105.03 & 2.27 \\
\hline 8 & 131.60 & 136.26 & 3.54 \\
\hline 9 & 136.10 & 144.90 & 6.47 \\
\hline 10 & 152.60 & 154.67 & 1.36 \\
\hline
\end{tabular}

TABle 9: Numerical frequencies and mode shapes for free-free configuration and pinned-supported configuration.

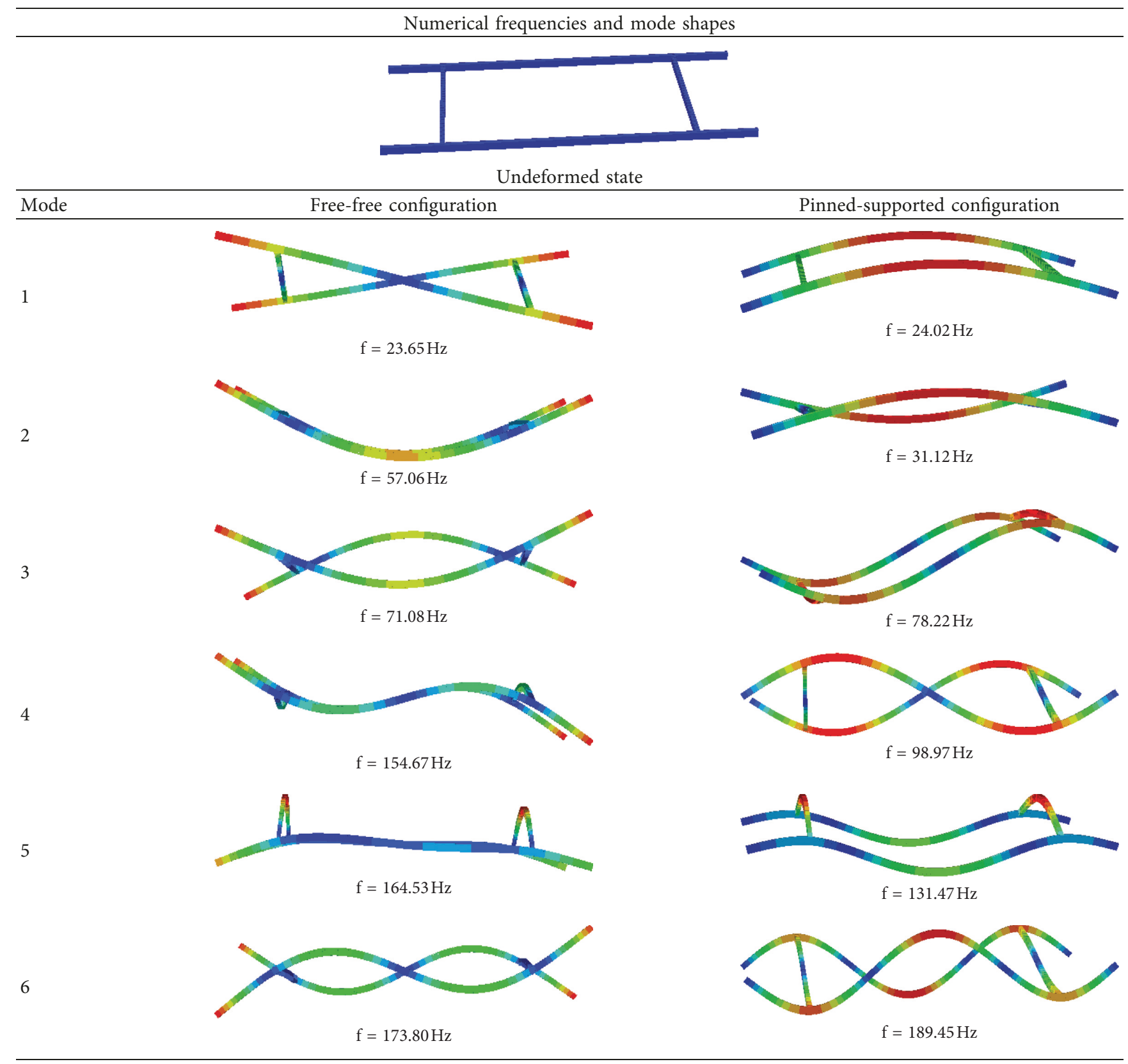




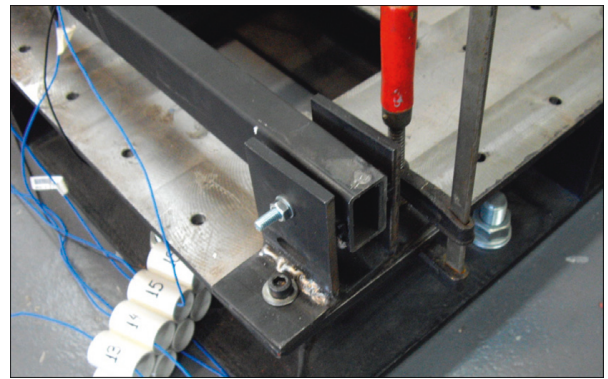

FIgURE 14: Details of the support.

TABLE 10: Experimental, numerical, and predicted natural frequencies for pinned-free configuration.

\begin{tabular}{lccccc}
\hline & & & Vertical axis & & \\
Mode & Natural frequency (Hz) & & \multicolumn{2}{c}{$\begin{array}{c}\text { Error (\%) } \\
\text { Experimental - numerical }\end{array}$} \\
& Experimental & Predicted (Equation (9)) & Numerical & Experimental - predicted & 4.87 \\
2 & 25.25 & 25.74 & 24.02 & -1.94 & 7.30 \\
3 & 33.57 & 33.88 & 31.12 & -0.92 & 3.05 \\
4 & 80.68 & 77.42 & 78.22 & 4.04 & 4.93 \\
5 & 104.10 & 95.02 & 98.97 & -3.72 & 3.10 \\
6 & 127.52 & 132.33 & 131.47 & -0.07 & 1.27 \\
\hline
\end{tabular}

shown in Figure 13 while the total mass of the structure is $21.94 \mathrm{~kg}$.

4.1. Free-Free Experimental Tests. The structure was initially tested in free-free configuration using operational modal analysis. The structure was suspended using two springs. Twelve accelerometers in the vertical direction with a sensitivity of $100 \mathrm{mv} / \mathrm{g}$ were attached to the structure. The test setup is shown in Figure 13.

The structure was excited with an impact hammer applying randomly hits both in time and in space. The responses were recorded with a sampling frequency of $2132 \mathrm{~Hz}$ during approximately 7 minutes. The experimental natural frequencies estimated with the frequencydomain decomposition technique are presented in Table 8 (for simplicity, the solid rigid motion frequencies are omitted) together with those obtained with a finite element model assembled in ABAQUS [22] where quadratic beam elements were used. The maximum discrepancy between both models is $8.26 \%$ (corresponding to the $2^{\text {nd }}$ mode). The numerical mode shapes are presented in Table 9.

4.2. Pinned-Supported Structure in Four Points. The SDM theory was applied to predict the natural frequencies and mode shapes of the structure with pinned supports in points A, B, C, and D (Figure 13). A detail of the support in point A is also shown in Figure 14.

Two solid rigid modes and six elastic modes of the freefree structure (Table 9) were used to predict the modal parameters of the structure pinned-supported in points $A, B$, $\mathrm{C}$, and D. A lumped mass matrix was assembled to normalize the mode shapes to the mass matrix. The pinned supports where simulated with a spring in the vertical direction with stiffness $K_{y}=10^{8} \mathrm{~N} / \mathrm{m}$. The natural frequencies predicted with Equation (9) are presented in Table 10.

Operational modal analysis was applied to the pinnedsupported structure using the test setup shown in Figure 15. The singular value decomposition of the responses is shown in Figure 16 where it can be observed that the first 6 vertical bending modes were identified in the frequency range $0-200 \mathrm{~Hz}$. The experimental natural frequencies obtained with the FDD technique are presented in Table 10. The discrepancies between the natural frequencies of the first 6 modes predicted with SMD theory and the experimental ones identified by OMA are less than $9 \%$. This error is of the same order as that existing between the numerical and the experimental modes, the error being less than $7.5 \%$.

With respect to the mode shapes, the MAC between the experimental mode shapes and those predicted with the SDM theory is presented in Table 11 from which it can be inferred that all the mode shapes are predicted with a good accuracy, the MAC being higher than 0.99.

\section{Conclusions}

Structural dynamic modification theory has been applied in this paper to predict the modal parameters of supported structures using the modal parameters of the same structures tested in free-free boundary conditions. This methodology could be used in a wide range of applications such as structures that are usually assembled in a factory and then transported to the site where the structure is to be located. A pinned-free beam, a cantilever beam, and a $3 \mathrm{D}$ steel beam were used to validate the proposed methodology. The 


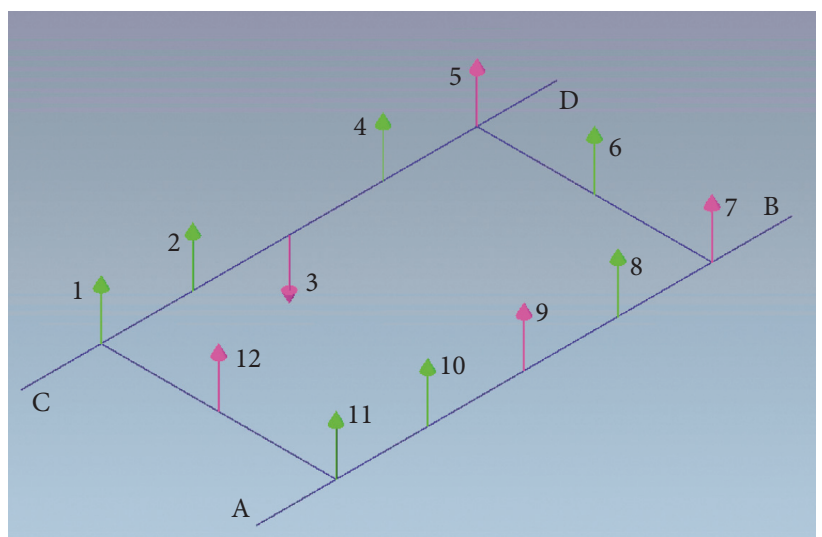

(a)

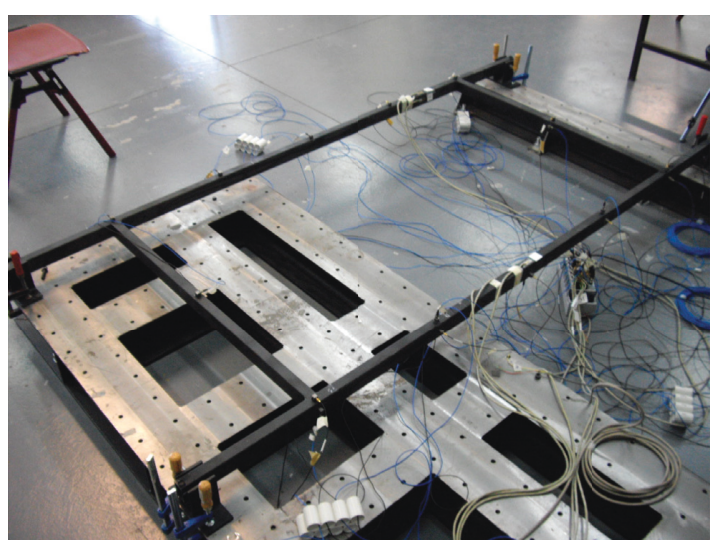

(b)

FIGURE 15: Test setup used in the experimental tests.

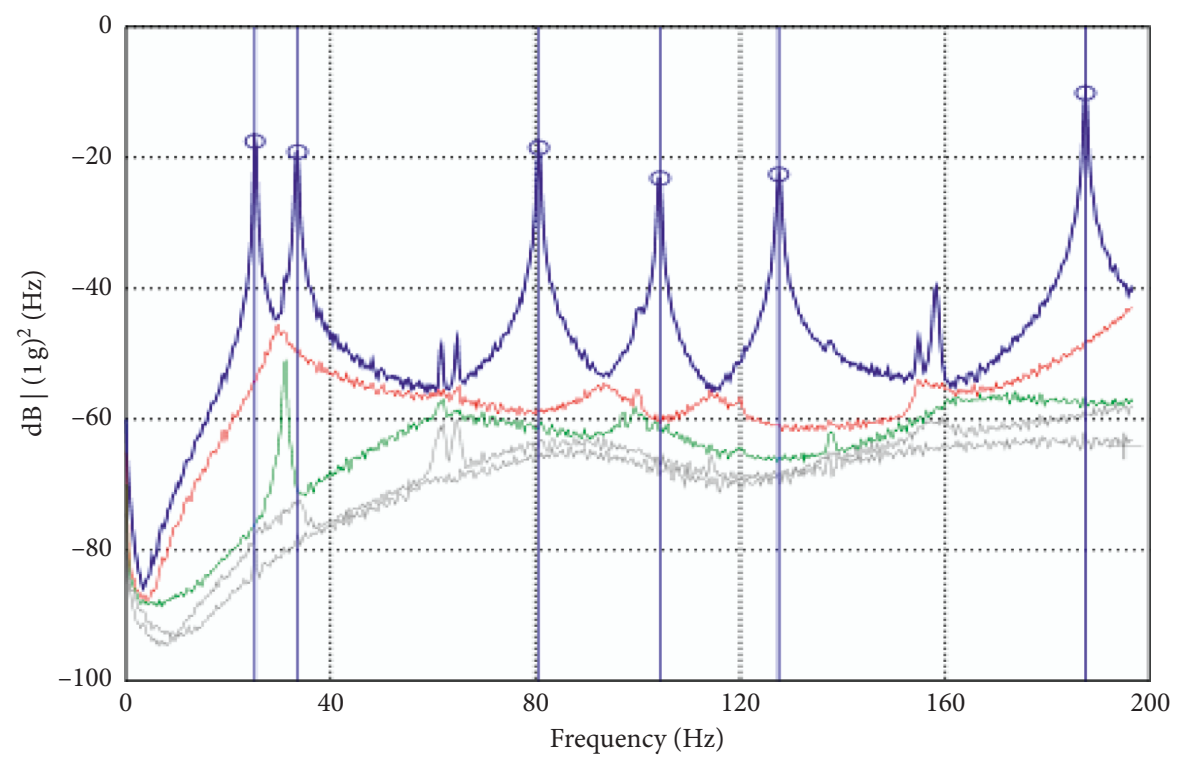

FIgURE 16: Singular value decomposition (SVD) in the frequency range $0-200 \mathrm{~Hz}$.

technique can be summarized in two steps: (1) to test the structure in free-free boundary conditions and estimation of the modal parameters using operational modal analysis and (2) to use the SDM theory to predict the modal parameters of the supported structures using Equation (9). Due to the fact that only unscaled mode shapes can be obtained with operational modal analysis (OMA), a lumped mass matrix was assembled and the mode shapes were normalized with Equation (13).

The technique has been validated by comparing the modal parameters predicted with SDM with those estimated with OMA. Accurate results have been obtained for pinnedsupported structures (error less than 10\%), whereas the fixed boundary condition is more difficult to replicate, the error being less than $16 \%$ in the natural frequencies.

It has been demonstrated that the technique provides good results when the boundary conditions considered in
TABLE 11: MAC between experimental and analytical mode shapes.

\begin{tabular}{lcccccc}
\hline \multirow{2}{*}{ Mode } & \multicolumn{7}{c}{ Vertical axis } \\
& 1 & 2 & 3 & 4 & 5 & 6 \\
\hline 1 & 1.00 & 0.03 & 0.00 & 0.00 & 0.01 & 0.00 \\
2 & 0.00 & 0.99 & 0.00 & 0.00 & 0.00 & 0.00 \\
3 & 0.00 & 0.06 & 1.00 & 0.00 & 0.00 & 0.13 \\
4 & 0.00 & 0.11 & 0.00 & 1.00 & 0.00 & 0.00 \\
5 & 0.01 & 0.00 & 0.00 & 0.00 & 0.99 & 0.00 \\
6 & 0.00 & 0.02 & 0.15 & 0.00 & 0.00 & 1.00 \\
\hline
\end{tabular}

Equation (9) reflect correctly the boundary conditions of the experimental test. Moreover, a numerical model of the structure is not needed with this methodology; that is, only the modal parameters of the unperturbed structures are used to predict the modal parameters of the perturbed structure, together with the mass, stiffness, and damping change matrices. 


\section{Data Availability}

The data used to support the findings of this study are available from the corresponding author upon request.

\section{Conflicts of Interest}

The authors declare that they have no conflicts of interest.

\section{Acknowledgments}

The financing support given by the Spanish Ministry of Economy and Competitiveness through the project BIA2011-28380-C02-01 is gratefully appreciated.

\section{References}

[1] S. Živanović, A. Pavic, and P. Reynolds, "Vibration serviceability of footbridges under human-induced excitation: a literature review," Journal of Sound and Vibration, vol. 279, no. 1-2, pp. 1-74, 2005.

[2] P. Dallard, T. Fitzpatrick, A. Flint et al., "The London millennium footbridge: pedestrian-induced lateral vibration," Journal of Bridge Engineering, vol. 6, no. 6, pp. 412-417, 2001.

[3] H. Bachmann, "Case studies of structures with man-induced vibrations," Journal of Structural Engineering, vol. 118, no. 3, pp. 631-647, 1992.

[4] J. H. Rainer, G. Pernica, and D. E. Allen, "Dynamic loading and response of footbridges," Canadian Journal of Civil Engineering, vol. 15, no. 1, pp. 66-71, 1988.

[5] E. T. Ingólfsson, C. T. Georgakis, and J. Jönsson, "Pedestrianinduced lateral vibrations of footbridges: a literature review," Engineering Structures, vol. 45, pp. 21-52, 2012.

[6] International Organization for Standardization, ISO 10137: 2007, Bases for Design of Structures-Serviceability of Buildings and Walkways Against Vibration, International Organization for Standardization, Geneva, Switzerland, 2007.

[7] S. Footbridges, Assessment of Vibrational Behavior of Footbridges under Pedestrian Loading, The Technical Department for Transport, Roads and Bridges Engineering and Road Safety, Paris, France, 2006.

[8] M. El-Sayed, T. M. Ebrahim, H. Abou-Elfath, and O. A. Ebrahim, "Evaluating the vertical vibration response of footbridges using a response spectrum approach," Alexandria Engineering Journal, vol. 52, no. 3, pp. 419-424, 2013.

[9] V. Racic, A. Pavic, and J. M. W. Brownjohn, "Experimental identification and analytical modelling of human walking forces: literature review," Journal of Sound and Vibration, vol. 326, no. 1-2, pp. 1-49, 2009.

[10] M. Friswell and J. E. Mottershead, Finite Element Model Updating in Structural Dynamics, Springer, Berlin, Germany, 1995.

[11] D. J. Ewins, Modal Testing: Theory and Practice, Vol. 15, Research Studies Press, Letchworth, UK, 1984.

[12] W. Heylen, S. Lammens, and P. Sas, Modal Analysis Theory and Testing, Katholieke Universiteit Leuven, Leuven, Belgium, 1997.

[13] R. Brincker and C. Ventura, Introduction to Operational Modal Analysis, Wiley, Hoboken, NJ, USA, 2015.

[14] M. Nad, "Structural dynamic modification of vibrating systems," Applied Computational Mechanics, vol. 1, pp. 203-214, 2007.

[15] A. Sestieri, "Structural dynamic modification," Sadhana, vol. 25, no. 3, pp. 247-259, 2000.
[16] P. Avitabile, "Twenty years of structural dynamic modification: a review," SV Sound and Vibration, vol. 37, no. 1, pp. 14-27, 2003.

[17] R. Brincker, L. Zhang, and P. Andersen, "Output-only modal analysis by frequency domain decomposition," Smart Materials and Structures, vol. 10, no. 3, pp. 441-445, 2001.

[18] LISA, Finite Element Analysis Software.

[19] M. López-Aenlle, R. Brincker, F. Pelayo, and A. F. Canteli, "On exact and approximated formulations for scaling-mode shapes in operational modal analysis by mass and stiffness change," Journal of Sound and Vibration, vol. 331, no. 3, pp. 622-637, 2012.

[20] R. Brincker and P. Andersen, "A way of getting scaled mode shapes in output only modal analysis," in Proceedings of International Modal Analysis Conference (IMAC-XXI), Kissimmee, FL, USA, February 2003.

[21] R. Brincker, A. Skafte, M. López-Aenlle, A. Sestieri, W. D'Ambrogio, and A. Canteli, "A local correspondence principle for mode shapes in structural dynamics," $\mathrm{Me}$ chanical Systems and Signal Processing, vol. 45, no. 1, pp. 91-104, 2014.

[22] ABAQUS, Finite Element Analysis Software, Dassault Systemes, Vélizy-Villacoublay, France. 


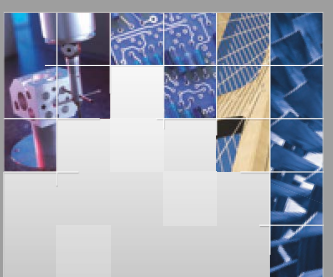

\section{Enfincering}
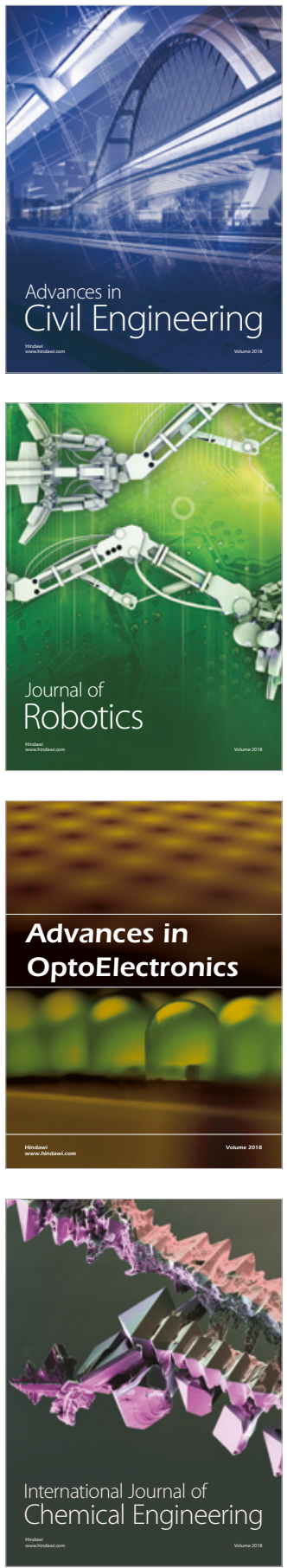

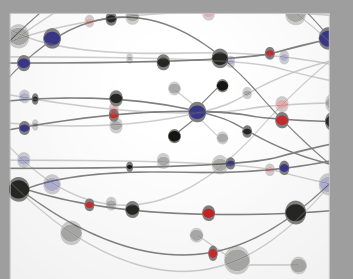

\section{Rotating \\ Machinery}

The Scientific World Journal

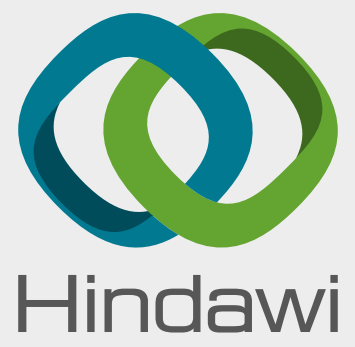

Submit your manuscripts at

www.hindawi.com
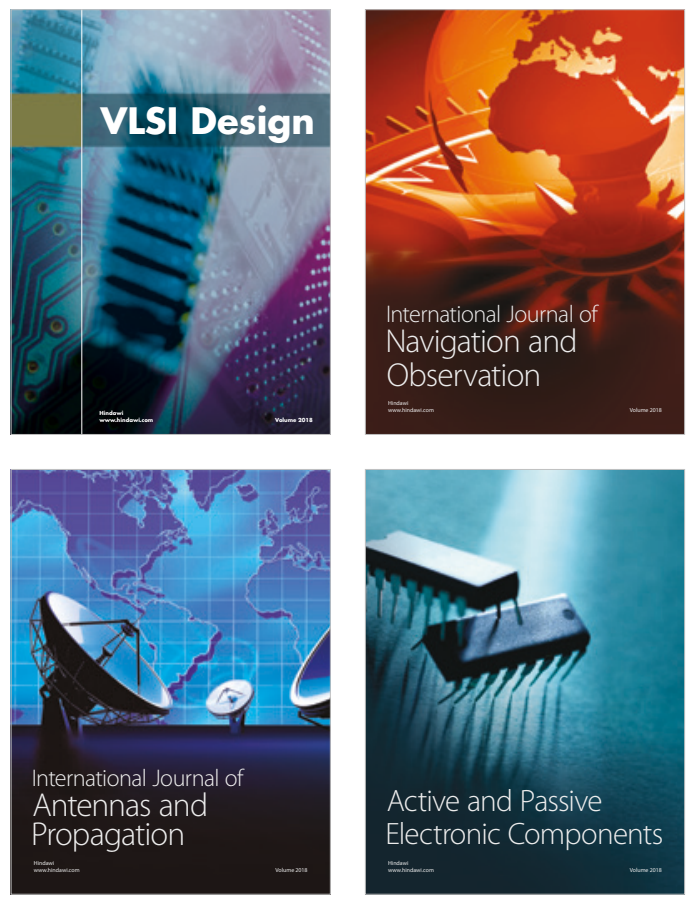
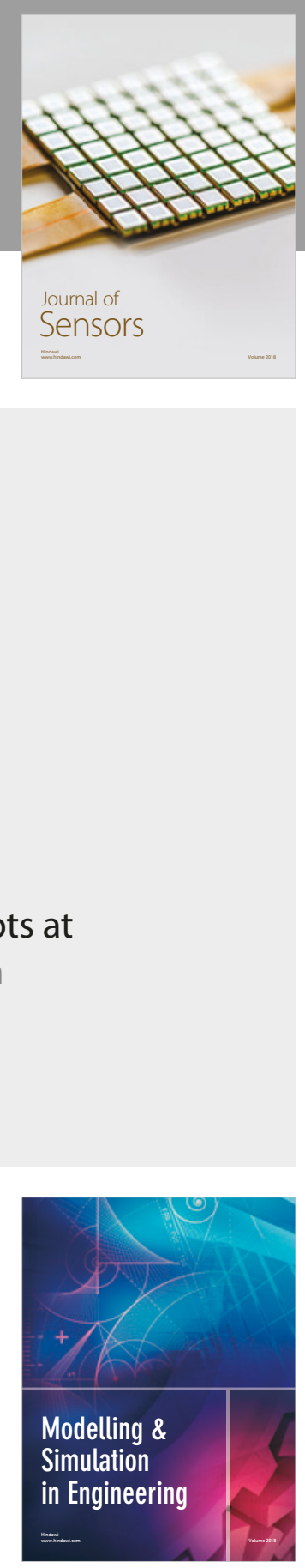

\section{Advances \\ Multimedia}
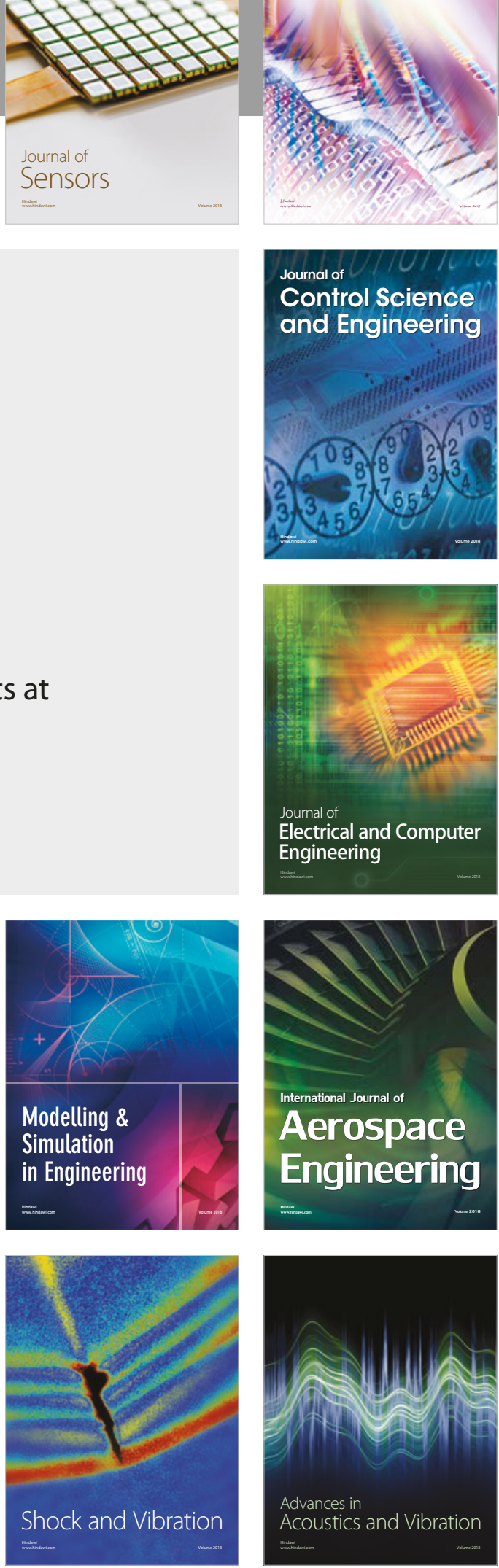